\title{
Epidemiology of Hypertriglyceridemia in the Elderly Taiwanese Population
}

\author{
Cheng-Chieh Lin ${ }^{\dagger}$, M.D., Tsai-Chung Li§, Ph.D., \\ Shih-Wei Lai*†, M.D., Chia-Ing Li ${ }^{\dagger}$, M.H.A., \\ Kuo-Che Wang ${ }^{\dagger}$, M.D., Chee-Keong Tan ${ }^{\dagger}$, M.D., M.BA., \\ Kim-Choy Ng ${ }^{\ddagger}, M . D$., Chiu-Shong Liu ${ }^{\dagger}$, M.D.
}

\begin{abstract}
Our study used data collected in Chung-Hsing Village in Taiwan in May 1998 to evaluate the distribution of triglycerides and the association between hypertriglyceridemia and its correlates in elderly people. All individuals aged 65 and over were recruited as study subjects. A total of 1093 persons, out of 1774 registered residents, were contacted in face-to-face interviews. The response rate was $61.6 \%$. However, only 586 respondents had blood tests and completed questionnaires. Analysis in this study was based on these 586 subjects. To study the significant correlates of hypertriglyceridemia, t-tests, ANOVAs, chi-square analysis and multivariate logistic regression were used. Among the study population, $66.0 \%$ were men and $34.0 \%$ were women. The mean age was $73.1 \pm 5.3$ years. The mean triglyceride values were $1.65 \pm 0.93 \mathrm{mmol} / \mathrm{L}$ in men and $2.02 \pm 1.44 \mathrm{mmol} / \mathrm{L}$ in women $(p<0.01)$. The proportions of hypertriglyceridemia were $18.7 \%$ in men and $27.6 \%$ in women $(p<0.05)$. After controlling the other covariates, analysis by multivariate logistic regression showed that the factors significantly related to hypertriglyceridemia were high systolic pressure, abnormal glutamic pyruvic transaminase, hypercholesterolemia and hyperglycemia. Thus, these results support the hypothesis that it is important to examine the other cardiovascular risk factors if one cardiovascular risk factor is observed. The data also suggest one should determine the triglyceride level when abnormal glutamic pyruvic transaminase is identified in an elderly subject.
\end{abstract}

\section{INTRODUCTION}

Risk factors for cardiovascular disease include hypertriglyceridemia, hypercholesterolemia, low serum high density lipoprotein (HDL) cholesterol,

\footnotetext{
* To whom correspondence should be addressed: Shih-Wei Lai, Department of Community Medicine, China Medical College Hospital, No 2, Yuh-Der Road, Taichung, 404, Taiwan. E-mail: shihweil@ms2.hinet.net

$\dagger$ Department of Community Medicine, China Medical College Hospital, Taichung, Taiwan.

$\S$ Institute of Chinese Medicine, China Medical College, Taichung, Taiwan.

$¥$ Department of Emergency, China Medical College Hospital, Taichung, Taiwan.
}

hypertension, diabetes mellitus, obesity, cigarette smoking, physical inactivity, increased age, prior cardiovascular disease, and left ventricular hypertrophy (1). The greater the number of the cardiovascular risk factors, the higher the incidence of new cardiovascular events (1). In Taiwan, cardiovascular disease is the third leading cause of death after neoplasm and cerebrovascular disease (2). The population of Taiwan is over 21 million and the population aged 65 and over has exceeded 7.0\% since 1994 (3). Hypertriglyceridemia has been identified as a modifiable risk factor for the cardiovascular disease in elderly people (4). Up to now, there is little information on the 
Table 1. Triglyceride levels (mmol/L) and proportion of hypertriglyceridemia $(\%)$ by age and gender in the elderly

\begin{tabular}{lcccc}
\hline Age (years) & Triglyceride & $\boldsymbol{p}$ & Hypertriglyceridemia & $\boldsymbol{p}$ \\
\hline Men & & & & \\
$65-69$ & $1.79 \pm 1.05$ & $\mathrm{NS}$ & 21.9 & $\mathrm{NS}$ \\
$70-74$ & $1.66 \pm 1.00$ & $\mathrm{NS}$ & 20.3 & $\mathrm{NS}$ \\
$75-79$ & $1.54 \pm 0.74$ & $<0.05$ & 17.2 & $\mathrm{NS}$ \\
$\geq 80$ & $1.57 \pm 0.90$ & $\mathrm{NS}$ & 10.9 & $\mathrm{NS}$ \\
subtotal & $1.65 \pm 0.93$ & $<0.01$ & 18.7 & $<0.05$ \\
& & & & \\
Women & & & & \\
$65-69$ & $1.94 \pm 1.20$ & $\mathrm{NS}$ & 24.3 & $\mathrm{NS}$ \\
$70-74$ & $1.99 \pm 1.40$ & $\mathrm{NS}$ & 24.6 & $\mathrm{NS}$ \\
$75-79$ & $2.32 \pm 1.89$ & $<0.05$ & 40.0 & $\mathrm{NS}$ \\
$\geq 80$ & $1.58 \pm 0.81$ & $\mathrm{NS}$ & 19.2 & $\mathrm{NS}$ \\
subtotal & $2.02 \pm 1.44$ & $<0.01$ & 27.6 & $<0.05$ \\
& & & & \\
\hline
\end{tabular}

NS: not significant

association between hypertriglyceridemia and its correlates in elderly Taiwanese people. As a result, health promotion and disease prevention recommendations for elderly people remain uncertain Thus, it is clearly time to pay closer attention to the health status of elderly people in this country.

Triglyceride levels were investigated through a comprehensive health survey in elderly people living in Chung-Hsing village in Taiwan in order to allow early detection of hypertriglyceridemia, identification of its related risk factors and early intervention for hypertriglyceridemia. The associations between hypertriglyceridemia and other variables were also reported.

\section{MATERIALS AND METHODS}

In May 1998, a cross-sectional study was conducted in Chung-Hsing Village in Taiwan. All individuals aged 65 and over were considered for the study, totaling 1774 subjects according to the official household registration records. A total of 1093 persons participated in this study giving a response rate of $61.6 \%$. However, only 586 respondents had blood tests and completed questionnaires. Analysis in this study was based on these 586 subjects. Information about the subject's socioeconomic status, family structure, and educational level was collected by well-trained interviewers in face-to-face interviews.

The subject's educational level was classified as: junior high school or less; some senior high school; some professional training college; and undergraduate or graduate degrees. If the subject had retired from work, that status was identified. If the subject still lived with a spouse, the marital status was defined as living together. If not, the marital status was defined as living alone.
Blood pressure was measured by a mercury sphygmomanometer in the sitting position. Weight and height were measured. Blood samples were obtained in the morning after a 12-hour overnight fast. A number of biochemical markers, such as glutamic pyruvic transaminase (GPT; also known as alanine aminotransaminase), total cholesterol, triglyceride, fasting glucose and uric acid were analyzed using a biochemical autoanalyser $\left(\mathrm{Chem} 1^{+}\right.$, Technicon, USA) at the Department of Clinical Laboratory of Chung-Hsing Hospital within 4 hours of collection.

Body mass index (BMI) was obtained using the formula: weight/height ${ }^{2}\left(\mathrm{~kg} / \mathrm{m}^{2}\right)$. BMI $\geq 28$ was defined as obese, BMI 25-27.9 as overweight, BMI 20-24.9 as normal and BMI $<20$ as underweight (5). Abnormal GPT were defined as GPT >30 U/L (6). Hypercholesterolemia was defined as total cholesterol $\geq 5.18 \mathrm{mmol} / \mathrm{L}$ and hypertriglyceridemia was defined as triglyceride $\geq 2.26 \mathrm{mmol} / \mathrm{L} \mathrm{(7).} \mathrm{Hyperglycemia} \mathrm{was}$ defined as fasting glucose $\geq 6.05 \mathrm{mmol} / \mathrm{L}$ (8). Subjects were considered to have high blood pressure if the average of three readings exceeded $140 \mathrm{mmHg}$ systolically and/or $90 \mathrm{mmHg}$ diastolically (9). Hyperuricemia was defined as serum uric acid $\geq 416.5$ $\mathrm{mmol} / \mathrm{L}$ in men and $\geq 386.8 \mathrm{mmol} / \mathrm{L}$ in women (10).

The statistical analysis was performed with the aid of a SAS package (Version 6.12, SAS Institute Inc., Cary, North Carolina). The methods of the statistical analysis applied in this study included the t-test, ANOVA, chi-square analysis and multivariate logistic regression. A $p$ value less than 0.05 was considered statistically significant.

\section{RESULTS}

Among the original 1093 subjects, $65.7 \%$ were men and $34.3 \%$ were women with a mean age of $73.5 \pm 5.6$ years. Among the final study population of 586 subjects, $66.0 \%$ were men and $34.0 \%$ were women with a mean age of $73.1 \pm 5.3$ years. We performed chi-square analysis and t-test to examine the gender and age distributions between these two samples. No significant difference was observed, suggesting that any bias introduced by nonresponders was minimal.

In Table 1 , the mean triglyceride value was $1.65 \pm$ $0.93 \mathrm{mmol} / \mathrm{L}$ in men and $2.02 \pm 1.44 \mathrm{mmol} / \mathrm{L}$ in women $(p<0.01)$. Although women seemed to have higher triglyceride values than men of similar ages, the difference was statistically significant only at age 75-79 $(p<0.05)$. The proportions of hypertriglyceridemia were $18.7 \%$ in men and $27.6 \%$ in women $(p<0.05)$. The proportion of hypertriglyceridemia decreased with age in men, but no statistical significance was noted. There was also no 
Table 2. Correlates of hypertriglyceridemia in the elderly by chisquare analysis

\begin{tabular}{|c|c|c|c|}
\hline Variable & Total & $\begin{array}{c}\text { Hypertriglyceridemia } \\
\text { Number }(\%)\end{array}$ & $p$ \\
\hline \multicolumn{4}{|l|}{ Body mass index $\left(\mathrm{kg} / \mathrm{m}^{2}\right)$} \\
\hline$<28$ & 498 & $101(20.28)$ & 0.042 \\
\hline$\geq 28$ & 69 & $22(31.88)$ & \\
\hline \multicolumn{4}{|l|}{ Systolic pressure $(\mathrm{mm} \mathrm{Hg})$} \\
\hline$<140$ & 378 & $66(17.46)$ & 0.004 \\
\hline$\geq 140$ & 196 & $55(28.06)$ & \\
\hline \multicolumn{4}{|l|}{ Diastolic pressure $(\mathrm{mm} \mathrm{Hg})$} \\
\hline$<90$ & 451 & $96(21.29)$ & 0.915 \\
\hline$\geq 90$ & 123 & $25(20.33)$ & \\
\hline \multicolumn{4}{|l|}{ GPT (U/L) } \\
\hline$\leq 30$ & 413 & $79(19.13)$ & 0.019 \\
\hline$>30$ & 165 & $47(28.48)$ & \\
\hline \multicolumn{4}{|l|}{ Total cholesterol $(\mathrm{mmol} / \mathrm{L})$} \\
\hline$<5.18$ & 296 & $38(12.84)$ & 0.001 \\
\hline$\geq 5.18$ & 286 & $88(30.77)$ & \\
\hline \multicolumn{4}{|l|}{ Fasting glucose $(\mathrm{mmol} / \mathrm{L})$} \\
\hline$<6.05$ & 464 & $83(17.89)$ & 0.001 \\
\hline$\geq 6.05$ & 117 & $43(36.75)$ & \\
\hline \multicolumn{4}{|l|}{ Uric acid $(\mu \mathrm{mol} / \mathrm{L})$} \\
\hline men $<416.5$, women $<386.8$ & 281 & $50(17.79)$ & 0.035 \\
\hline men $\geq 416.5$, women $\geq 386.8$ & 300 & $76(25.33)$ & \\
\hline \multicolumn{4}{|l|}{ Educational level } \\
\hline junior high school or less & 164 & $41(25.00)$ & 0.251 \\
\hline senior high school & 151 & $29(19.21)$ & \\
\hline professional training college & 72 & $10(13.89)$ & \\
\hline undergraduate or graduate & 132 & $27(20.45)$ & \\
\hline \multicolumn{4}{|l|}{ Retirement status } \\
\hline non-retired & 150 & $41(27.33)$ & 0.065 \\
\hline retired & 432 & $85(19.68)$ & \\
\hline \multicolumn{4}{|l|}{ Marital status } \\
\hline living together & 424 & $82(19.34)$ & 0.047 \\
\hline living alone & 157 & $43(27.39)$ & \\
\hline
\end{tabular}

relationship between hypertriglyceridemia and age in women.

The results of chi-square analysis for hypertriglyceridemia and its correlates are shown in Table 2. The significant correlates of hypertriglyceridemia were obesity, high systolic pressure, abnormal GPT, hypercholesterolemia, hyperglycemia, hyperuricemia and marital status.

The results of multivariate logistic regression for hypertriglyceridemia and its correlates are shown in Table 3. After controlling for other covariates, the significant correlates of hypertriglyceridemia were high systolic pressure (odds ratio $[\mathrm{OR}]=2.29,95 \%$ confidence intervals $[\mathrm{CI}]=1.30-4.03, p<0.01)$, abnormal GPT $(\mathrm{OR}=1.99,95 \% \mathrm{CI}=1.07-3.70, p<$ $0.05)$, hypercholesterolemia $(\mathrm{OR}=2.62,95 \% \mathrm{CI}=$ $1.45-4.74, p<0.01)$, hyperglycemia $(\mathrm{OR}=2.22,95 \%$ $\mathrm{CI}=1.16-4.26, p<0.05)$. In other words, people with high systolic pressure were more likely to have hypertriglyceridemia than people with normal
Table 3. Results of multivariate logistic regression for hypertriglyceridemia in the elderly

\begin{tabular}{|c|c|c|c|}
\hline Variable & EP (SE) & OR & $95 \% \mathrm{CI}$ \\
\hline $\begin{array}{l}\text { Intercept } \\
\text { Gender }\end{array}$ & $-3.11(0.38)$ & & \\
\hline $\begin{array}{l}\text { women (men as ref.) } \\
\text { Body mass index }\end{array}$ & $0.46(0.31)$ & 1.58 & $0.86-2.92$ \\
\hline Obese (normal as ref.) & $0.15(0.35)$ & 1.17 & $0.59-2.30$ \\
\hline $\begin{array}{l}\text { Systolic pressure } \\
\geq 140 \text { ( }<140 \text { as ref.) }\end{array}$ & $0.83(0.29)$ & 2.29 & $1.30-4.03^{* *}$ \\
\hline $\begin{array}{l}\text { Glutamic pyruvic transaminase } \\
\quad>30 \text { ( } \leq 30 \text { as ref.) }\end{array}$ & $0.69(0.32)$ & 1.99 & $1.07-3.70^{*}$ \\
\hline $\begin{array}{l}\text { Total cholesterol } \\
\geq 5.18 \text { (<5.18 as ref.) }\end{array}$ & $0.96(0.30)$ & 2.62 & $1.45-4.74^{* *}$ \\
\hline $\begin{array}{l}\text { Fasting glucose } \\
\geq 6.05(<6.05 \text { as ref. })\end{array}$ & $0.80(0.33)$ & 2.22 & $1.16-4.26^{*}$ \\
\hline Uric acid (men, women ) & & & \\
\hline $\begin{array}{l}\geq 416.5(<416.5 \text { as ref. in men }) \\
\geq 386.8(<386.8 \text { as ref. in women })\end{array}$ & $0.55(0.30)$ & 1.73 & $0.97-3.10$ \\
\hline $\begin{array}{l}\text { Marital status } \\
\text { living alone (living }\end{array}$ & $0.29(0.33)$ & 1.34 & $0.71-2.54$ \\
\hline
\end{tabular}

EP: Estimated Parameter; SE: Standard Error; OR: Odds Ratio; CI: Confidence Interval. ${ }^{*} p<0.05,{ }^{* *} p<0.01$

systolic pressure. People with abnormal GPT were more likely to have hypertriglyceridemia than people with normal GPT. People with hypercholesterolemia were more likely to have hypertriglyceridemia than people with normal total cholesterol. People with hyperglycemia were more likely to have hypertriglyceridemia than people with normal fasting glucose.

\section{DISCUSSION}

Most people living in Chung-Hsing Village moved to Taiwan from Mainland China after the civil war during their military service. Because most of them were male, the proportion of male in our study was higher than that of female.

In Larosa's report, triglyceride levels increase in the elderly and is one predictor of cardiovascular disease in elderly people (11). In the present study, we found no relationship between triglyceride levels and age in elderly people. This might be due to genetic, racial, environmental, or dietary differences in the sampling population, but the real cause needs further investigation.

In Chou's study, the mean triglyceride values were $1.92 \pm 1.32 \mathrm{mmol} / \mathrm{L}$ in men and $1.76 \pm 1.28 \mathrm{mmol} / \mathrm{L}$ in women. The prevalence of hypertriglyceridemia $(\geq 2.26 \mathrm{mmol} / \mathrm{L})$ was $26.7 \%$ in men and $23.8 \%$ in women (12). In Huang's report, The prevalence of hypertriglyceridemia $(>1.86 \mathrm{mmol} / \mathrm{L})$ was $15.7 \%$ in elderly men and $26.0 \%$ in elderly women (13). 
However, in our present report, the prevalence of hypertriglyceridemia was $18.7 \%$ in men and $27.6 \%$ in women. Differences in prevalence of hypertriglyceridemia might be due to the different measurement tools, different diagnostic criteria or different population though, in general, hypertriglyceridemia was commonly found in the elderly population in all three studies. Therefore, it is important to examine serum triglyceride levels periodically in elderly people. Early detection of hypertriglyceridemia and early intervention for hypertriglyceridemia should be performed.

In our report, hypertriglyceridemia was significantly associated with high systolic pressure, hypercholesterolemia and hyperglycemia. In previous studies, hyperlipidemia was often associated with obesity, diabetes, and hyperuricemia (10,14-17). In our previous report, hyperglycemia was significantly correlated with hypertriglyceridemia (18). In Austin's report, hypertriglyceridemia was a risk factor for the cardiovascular disease (19). Other studies indicate that the cardiovascular risk factors often cluster within the same individual $(10,14-20)$. Thus, it is important to determine the other cardiovascular risk factors if one cardiovascular risk factor is observed.

GPT catalyzes the transfer of the amino group of alanine to glutaric acid, forming glutamic acid and pyruvic acid. Elevated serum GPT usually indicates liver damage (21). In our report, hypertriglyceridemia was significantly associated with abnormal GPT. This might be explained by a mechanism whereby hypertriglyceridemia resulted in fatty change in the liver and fat accumulation in the cytoplasm of hepatocytes, leading to leakage of cytoplasmic GPT into the blood (6). As a result, increased serum GPT activities would be detected.

In conclusion, hypertriglyceridemia is significantly associated with high systolic pressure, hypercholesterolemia, and hyperglycemia in elderly Taiwanese people. Thus, it is important to examine the other cardiovascular risk factors if one cardiovascular risk factor is demonstrated. It is also suggested that one determine triglyceride levels when abnormal GPT is disclosed in the elderly people.

\section{ACKNOWLEDGEMENTS}

This study was supported by grants from the Health Department, Taiwan Province. We thank Miss MeiYen Li and Miss Hsing-Yi Chan for assistance with statistical analysis in preparing this manuscript and the personnel of Chung-Hsing Hospital for their full cooperation.

\section{REFERENCES}

1. Aronow WS. Cardiac risk factors: still important in the elderly. Geriatrics 1990; 45: 71-74, 79-80.

2. Department of Health. Taiwan: General health statistics; 1999.

3. National Health Administration. Taiwan: Health statistics: I. Vital statistics; 1971-1996.

4. Aronow WS, Herzig AH, Etienne F, et al. 41-month followup of risk factors correlated with new coronary events in 708 elderly patients. Journal of the American Geriatric Society 1989; 37: 501-506.

5. Huang PC, Yu SL, Lin YM, Chu CL. Body weight of Chinese adults by sex, age and body height and criterion of obesity based on body mass index. Journal of the Clinical Nutrition Society 1992; 17: 157-172.

6. Noguchi H, Tazawa Y, Nishinomiya F, Takada G. The relationship between serum transaminase activities and fatty liver in children with simple obesity. Acta Paediatrica Japonica 1995; 37: 621-625.

7. Summary of the second report of the National Cholesterol Education Program (NCEP) Expert Panel on Detection, Evaluation, and Treatment of High Blood Cholesterol in Adults (Adult Treatment Panel II). JAMA 1993; 269: 3015-3023.

8. The expert committee on the diagnosis and classification of diabetes mellitus: report of the expert committee on the diagnosis and classification of diabetes mellitus. Diabetes Care 2000; 23: 4-19.

9. Summary of 1993 World Health Organization - International Society of Hypertension guidelines for the management of mild hypertension. Subcommittee of WHO/ISH Mild Hypertension Liaison Committee. BMJ 1993; 307: 15411546.

10. Saggiani F, Pilati S, Targher G, et al. Serum uric acid and related factors in 500 hospitalized subjects. Metabolism 1996; 45: 1557-1561.

11. LoRosa JC. Triglycerides and coronary risk in women and the elderly. Archives of Internal Medicine 1997; 157: 961968.

12. Chou P, Hsiao KJ, Lin WH, Chen ST. Community-based survey on blood pressure, blood biochemistry and dietary habits in Pu-Li, Taiwan. Chinese Medical Journal (Taipei) 1992; 50: 279-287.

13. Huang HC, Tjung JJ, Tsai YC, et al. The results of physical check-ups in the elderly aged over 65 at Mackay memorial hospital in Taipei city - preliminary report. Chinese Journal of Family Medicine 1993; 3: 27-38.

14. Woo J, Swaminathan R, Cockram C, et al. Association between serum uric acid and some cardiovascular risk factors in a Chinese population. Postgraduate Medical Journal 1994; 70: 486-491.

15. Agamah ES, Srinivasan SR, Webber LS, Berenson GS. Serum uric acid and its relation to cardiovascular disease risk factors in children and young adults from a biracial community: the Bogalusa Heart Study. Journal of Laboratory and Clinical Medicine 1991; 118: 241-249.

16. Chen TJ, Yu BT. Report on survey of serum glucose, cholesterol, uric acid and creatinine values in adults of Taipei city. Journal of Nephrology ROC 1995; 9: 109-118.

17. Lin CC, Li TC, Lai SW, et al. Hypertriglyceridemia and the related factors in middle-aged adults in Taiwan. Mid-Taiwan Journal of Medicine 2001; 6: 1-6.

18. Lai SW, Tan CK, Ng KC. Epidemiology of hyperglycemia in elderly persons. Journal of Gerontology A Biological Sciences and Medical Sciences 2000; 55: 257-259. 
19. Austin MA, Hokanson JE, Edwards KL. Hypertriglyceridemia as a cardiovascular risk factor. American Journal of Cardiology 1998; 81: 7B-12B.

20. Ng KC, Lin CC, Lai SW, et al. Obesity and the related factors in middle-aged adults in Chung-Hsing village in
Taiwan. Mid-Taiwan Journal of Medicine 2001; 6: 35-39.

21. Rao GM, Morghom LO, Kabur MN, et al. Serum glutamic oxaloacetic transaminase and glutamic pyruvic transaminase levels in diabetes mellitus. Indian Journal of Medical Sciences 1989; 43: 118-121.

Dr. Cheng-Chieh Lin, M.D., is a Ph.D. candidate in Health Administration at the University of South Carolina. He is also an associate professor of family medicine and Superintendent of China Medical College Hospital (CMCH) in Taiwan, R.O.C. Dr. Tsai-Chung Li, Ph.D., from the University of Michigan, is an associate professor in the Institute of Chinese Medicine, CMCH. Dr. Shih-Wei Lai, M.D., is a visiting staff in the Department of Community Medicine, CMCH. Chia-Ing Li, M.H.A., is a research assistant in the Department of Community Medicine, CMCH. Dr. Kuo-Che Wang, M.D., is a chief resident in the Department of Community Medicine, CMCH. Dr. Chee-Keong Tan, M.D., M.B.A., is a third-year resident in the Department of Community Medicine, CMCH. Dr. Kim-Choy Ng, M.D., is a visiting staff in the Department of Emergency, CMCH. Dr. Chiu-Shong Liu, M.D., is Director of the Department of Family Medicine, CMCH. 